\title{
Cytochrome c Oxidase Deficiency
}

\author{
SALVATORE DiMAURO, ANNE LOMBES, HIROFUMI NAKASE, SHUJI MITA, \\ GIAN MARIA FABRIZI, HANS-JURGEN TRITSCHLER, EDUARDO BONILLA, \\ ARMAND F. MIRANDA, DARRYL C. DEVIVO, AND ERIC A. SCHON
}

H. Houston Merritt Clinical Research Center for Muscular Dystrophy and Related Diseases, Columbia University College of Physicians and Surgeons, New York, New York 10032

\begin{abstract}
Cytochrome c oxidase (COX) is a complex enzyme composed of 13 subunits, three of which are encoded by the mitochondrial DNA (mtDNA). The other 10 subunits are encoded by the nuclear DNA, synthesized in the cytoplasm, and transported into the mitochondria. The complexity of the enzyme and its dual genetic control explain the heterogeneity of clinical phenotypes associated with COX deficiency. There are two major syndromes, one characterized by muscle involvement (fatal infantile or benign infantile myopathy), the other dominated by brain disease (Leigh syndrome, myoclonic epilepsy with ragged red fibers, Menkes' disease). Partial defects of COX have been shown in muscle of patients with progressive external ophthalmoplegia, either alone (ocular myopathy) or as part of Kearns-Sayre syndrome. Biochemical studies have documented either muscle-specific or generalized defects of COX; COX deficiency is reversible in the benign infantile myopathy. Immunologically detectable protein may be normal (benign myopathy) or variably decreased (fatal myopathy, Leigh syndrome). The subunit pattern of $\mathrm{COX}$ is normal by immunoblot in patients with fatal myopathy and Leigh syndrome; a disproportionate decrease of subunit II was seen in a patient with myoclonic epilepsy with ragged red fibers. Availability of the three mtDNA genes and of complementary DNA probes for eight of the 10 nuclear DNA-encoded subunits makes it possible to investigate the different diseases at the molecular level. Large deletions of mtDNA have been found in patients with ocular myopathy and Kearns-Sayre syndrome: the deleted mtDNA appear to be transcribed but not translated, thus explaining the partial COX deficiency. (Pediatr Res 28: 536-541, 1990)
\end{abstract}

\section{Abbreviations}

COX, cytochrome c oxidase

PEO, progressive external ophthalmoplegia

mtDNA, mitochondrial DNA

nDNA, nuclear DNA

KSS, Kearns-Sayre syndrome

RRF, ragged red fibers

MERRF, myoclonic epilepsy with ragged red fibers

CRM, cross-reacting material

Reprint requests: Dr. Salvatore DiMauro, Room 4-420, College of Physicians and Surgeons, 630 West 168 th Street, New York, NY 10032.

Supported by Center grants from NINCDS (NS 11766) and the Muscular Dystrophy Association, and by a generous donation from Libero and Graziella Danesi. A.L. was supported by postdoctoral fellowships from the Fondation pour la Recherche Médicale. the Ministère Francais des Relations Extérieures, and the Muscular Dystrophy Association. H.-J.T. was supported by a fellowship from the DAAD, Bonn, West Germany.

\section{THE ENZYME}

COX, the last component of the respiratory chain (complex IV), catalyzes the transfer of reducing equivalents from cytochrome $c$ to molecular oxygen. The energy generated by this reaction sustains a transmembrane proton-pumping activity. The holoenzyme contains two (possibly three) copper atoms and two unique heme $\mathrm{A}$ iron porphyrins bound to a multisubunit protein frame embedded in the mitochondrial inner membrane $(1,2)$. In mammals, the apoprotein is composed of 13 subunits. The three larger polypeptides (subunits I to III) are associated with the prosthetic groups and perform both catalytic and protonpumping activities. They are encoded by mtDNA and are synthesized in mitochondria; both their coding sequences and primary structures have been established in humans (3). The 10 smaller subunits [IV, Va, Vb, VIa, VIb, VIc, VIIa, VIIb, VIIc, and VIII, according to the nomenclature of Kadenbach et al. (4)] are encoded by nDNA and synthesized in the cytoplasm. All except subunit VIII are synthesized as precursors carrying $\mathrm{NH}_{2}$ terminal basic presequences that allow them to be transported into the mitochondria $(5,6)$. The functions of the nDNAencoded subunits (which are missing in procaryotes) have not been fully elucidated, but they may modulate the catalytic function, optimizing it to the metabolic requirements of different tissues. In agreement with this concept was the demonstration (based on electrophoretic mobility, amino acid sequences, and antibody specificity) that some of the COX subunits are tissuespecific and developmentally regulated (2).

Characterization of the human nDNA-encoded subunits of $\mathrm{COX}$ at the molecular level has progressed very rapidly, and fulllength cDNA are now available for all subunits except VIIb and VIIc (7-14). When these cDNA were used as probes in Northern analyses of RNA isolated from different human tissues, it was found that only one subunit, VIa, is tissue specific. Although preliminary evidence suggests that subunit VIIa may also be tissue specific, a surprising result was that subunit VIII, for which at least two isoforms are known to exist in other species, is expressed as a single form in primates. So far, the only unequivocal chromosomal assignment has been obtained for the gene encoding COX VIII, which is localized to chromosome 11 (14).

\section{THE DISEASES}

COX deficiency was first reported in trichopoliodystrophy (Menkes' disease), an X-linked recessive disorder of copper metabolism causing infantile seizures, developmental regression, hair abnormalities, tortuous arteries, fragile bones, hypopigmentation, and temperature instability (15). These diverse manifestations have been attributed to secondary deficiencies of copperdependent enzymes, of which COX is one.

In 1977, the same group of investigators (15) reported COX deficiency in two unrelated and clinically different patients. Van Biervliet et al. (16) described an infant with severe generalized myopathy and renal dysfunction. There was no clinical involve- 
ment of other organs, and the child died of respiratory failure at 4 mo of age. There was complete lack of COX activity and cytochrome $\mathrm{aa}_{3}$ and partial defect of cytochrome $\mathrm{b}$ in muscle mitochondria.

The second patient was a girl who died of respiratory insufficiency at $6 \mathrm{y}$ of age after suffering from a syndrome that included ataxia, optic atrophy, and dementia (17). Neuropathologic examination showed the characteristic lesions of subacute necrotizing encephalomyelopathy (Leigh syndrome). COX activity was undetectable in muscle mitochondria and decreased in heart, but normal in liver.

During the years that followed, numerous other cases of COX deficiency were reported, most of which fall into two groups exemplified by the two patients described in 1977: in one group myopathy is the principal, if not the only, manifestation; in the other group, a multisystem disorder is dominated by brain disease (Table 1).

Myopathies. Two forms of myopathy have been described, both presenting soon after birth with severe generalized weakness, respiratory distress, and lactic acidosis, but each having a very different course and prognosis. Children with fatal infantile myopathy have a relentlessly downhill course and die of respiratory failure before 1 y of age $(16,18-25)$. Although heart, liver, and brain are clinically spared, many patients have renal disease with glycosuria, phosphaturia, and generalized aminoaciduria (De Toni-Fanconi syndrome). Pedigree analysis in informative families suggests autosomal recessive transmission. Different clinical phenotypes, probably not related genetically to the fatal infantile myopathy, are characterized by the association of myopathy and cardiomyopathy in the same patient $(26,27)$, or by the coexistence of myopathy and hepatopathy in the same family [but not in the same patients (28)].

Children with benign infantile myopathy also present with severe weakness and often need assisted ventilation and gavage feeding early in life, but improve spontaneously and are usually normal by 2 or 3 y of age $(25,29-31)$. Lactic acidosis, which is initially even more severe than in the fatal form, also remits spontaneously. Although potentially benign, this myopathy is life-threatening in the first months of life; therefore, it would be important to identify pathologic or biochemical features that might help in the differential diagnosis between fatal infantile and benign myopathies.
Partial defects of COX, sometimes manifested only by scattered histochemically negative fibers in muscle biopsies, are commonly seen in patients with $\mathrm{PEO}$ and morphologic alterations of mitochondria [RRF (32-34)]. The pathogenic significance of this partial COX deficiency remained unclear until recently, when molecular genetic analysis provided a logical explanation for this finding (see below).

Encephalomyopathies. A number of multisystem disorders dominated clinically by brain dysfunction have been associated with generalized COX deficiency. The most common appears to be subacute necrotizing encephalomyelopathy (Leigh syndrome): 22 patients have been reported $(17,35-42)$, and we have recently encountered 14 more (Van Coster R, Lombes A, DeVivo DC, Chi TL, Dodson E, Rothman S, Orrecchio EJ, Grover W, Berry GT, Schwartz JF, Habib A, DiMauro S, unpublished observations). Leigh syndrome is a devastating encephalopathy of infancy or childhood, characterized by psychomotor regression, that usually becomes manifest around 1 y of age and is accompanied by a spectrum of neurologic signs including ataxia, optic atrophy, ophthalmoplegia, ptosis, nystagmus, dystonia, tremor, pyramidal signs, and respiratory abnormalities. The characteristic neuropathologic lesions are symmetrical areas of necrosis involving preferentially mid-brain, pons, basal ganglia, thalamus, and optic nerves. Microscopically, there is cystic cavitation, vascular proliferation, neuronal loss, and demyelination. Muscle histochemistry is normal, but electron microscopy may show an increased number of mitochondria. Two or more siblings were affected in six families and there was parental consanguinity in two, suggesting autosomal recessive transmission. However, the predominance of affected males ( 21 of 32 patients) is unexplained. Leigh syndrome may be due to other biochemical causes, such as pyruvate dehydrogenase complex deficiency, and the biochemical error remains unknown in many patients.

COX deficiency was also shown in muscle biopsies from two unrelated patients with Alpers disease (progressive sclerosing poliodystrophy), a neurodegenerative disorder of infancy dominated by intractable epilepsy and associated with liver disease (43).

COX deficiency has been found in still another mitochondrial encephalomyopathy known by the acronym MERRF (44-47). As the name implies, MERRF is characterized by mitochondrial myopathy and myoclonus. Ataxia, generalized seizures, hearing

Table 1. COX deficiency: phenotypic expression and residual COX (\%)*

\begin{tabular}{|c|c|}
\hline Phenotype & Tissue(s) affected (\% COX) \\
\hline \multicolumn{2}{|l|}{ Disorders affecting muscle exclusively or predominantly } \\
\hline \multicolumn{2}{|l|}{ Fatal infantile myopathy } \\
\hline Myopathy only & Muscle $(<10 \%)$ \\
\hline Myopathy and nephropathy & Muscle $(<10 \%)$; kidney $(40 \%)$ \\
\hline Myopathy and cardiopathy & Muscle $(<10 \%)$; heart $(12 \%)$ \\
\hline Myopathy and hepatopathy & Muscle $(<10 \%)$; liver $(<10 \%)$ \\
\hline Benign infantile myopathy & Muscle $(<10 \%$ returning to normal) \\
\hline \multicolumn{2}{|l|}{ Disorders affecting predominantly the brain } \\
\hline \multirow[t]{3}{*}{ Subacute necrotizing encephalomyelopathy (Leigh syndrome) } & Muscle $(14 \%)$; brain $(32 \%)$ \\
\hline & Liver $(6 \%)$; kidney $(35 \%)$ \\
\hline & Heart (12\%); fibroblasts $(22 \%)$ \\
\hline Alpers syndrome & Muscle $(10 \% ; 42 \%)$ \\
\hline \multirow[t]{2}{*}{ MERRF } & Muscle $(30 \%)$; brain $(29 \%)$ \\
\hline & Heart ( $18 \%)$; liver $(41 \%)$ \\
\hline \multirow[t]{2}{*}{ Trichopoliodystrophy (Menkes' disease) } & Muscle (54\%); brain $(47 \%)$ \\
\hline & Heart (59\%); liver (23\%) \\
\hline \multicolumn{2}{|l|}{ Other } \\
\hline \multicolumn{2}{|l|}{ PEO } \\
\hline Ocular myopathy & Muscle (25\% normal) \\
\hline KSS & All tissues (variably decreased) \\
\hline Encephalomyopathy in adults & Muscle (28-43\%); brain (?) \\
\hline MNGIE syndromet & Muscle (18\%); liver (6\%) \\
\hline
\end{tabular}

* Modificd from Schon et al. (60).

$\dagger$ Myo-neuro-gastrointestinal encephalopathy. 
loss, and dementia are common additional features. This disorder is transmitted by nonmendelian, maternal inheritance, which implies a genetic defect of mtDNA (44-47). Neuropathologic alterations are most prominent in the dentate nucleus of the cerebellum and in the inferior olivary nuclei, with neuronal loss and gliosis (47)

Findings similar to those described above for patients with PEO and RRF (partial COX deficiency in muscle and histochemical evidence of COX-negative fibers) are seen in patients with a mitochondrial encephalomyopathy called KSS. KSS is characterized by the onset before age 20 of PEO and pigmentary retinopathy, plus at least one of the following: complete heart block, cerebrospinal fluid protein level above $100 \mathrm{mg} / \mathrm{dL}$, and cerebellar syndrome (48). Although some patients have features that are intermediate between pure PEO (ocular myopathy) and typical KSS, in our experience these patients with "probable KSS" are relatively few (48).

Other multisystem disorders with partial COX deficiency are less well characterized. One such syndrome has been called myoneuro-gastrointestinal encephalopathy because the patient, a German woman who died at age 42 , had had chronic malnutrition due to maladsorption, PEO, limb weakness and wasting, polyneuropathy, and computed tomography scan evidence of leukodystrophy (49). Muscle biopsy showed RRF, and COX activity was decreased in muscle and liver. We have recently studied a brother and sister of German descent (but unrelated to the first patient) who have a virtually identical clinical picture and partial COX deficiency in muscle (Lombes, unpublished observations). Their parents were first cousins, suggesting that myo-neuro-gastrointestinal encephalopathy is inherited as an autosomal recessive trait.

As mentioned above, COX deficiency appears to be a secondary phenomenon in trichopoliodystrophy (Menkes' disease).

\section{HISTOCHEMICAL, BIOCHEMICAL, AND IMMUNOLOGIC STUDIES}

Histochemical and biochemical studies of patients with different forms of COX deficiency provided the first independent support of Kadenbach's suggestion that there are tissue-specific COX isozymes. For instance, as suggested by clinical and pathologic observations, COX deficiency in patients with fatal infantile myopathy was confined to skeletal muscle, sparing heart, liver, and brain (21). Partial COX deficiency was documented in the kidney of patients with myopathy and nephropathy $(20,21)$ and in the heart of at least one patient with myopathy and cardiomyopathy (26). Muscle histochemistry confirmed the selective involvement of muscle: the enzyme stain was absent in extrafusal fibers but present in intrafusal fibers of muscle spindles and in smooth muscle of blood vessels $(22,50)$. Immunologic studies using antibodies against human heart COX holoenzyme showed a decreased amount of CRM in muscle of patients, both by ELISA and by immunocytochemistry (21). Electrophoretic study of the mutant enzyme after immunoprecipitation failed to show any alteration in the subunit pattern (21). However, availability of antibodies against the individual subunits now permits a more detailed analysis of the mutant enzyme. Immunohistochemistry of muscle from a patient showed lack of COX VIIb,c and decreased amounts of COX II and III (51), but in muscle biopsies from four other patients we found a selective defect of COX VIIa (51a). A defect of COX VIla would be in agreement with the suspected tissue-specific nature of this subunit, but these data have to be confirmed by Western analysis.

The spontaneous clinical recovery in children with the benign infantile myopathy correlates with a gradual return of COX activity in muscle, which can be demonstrated both histochemically and biochemically. In one patient, the enzyme activity increased from 6 to 33 to $174 \%$ of normal in biopsies taken at 2,7 , and 36 mo (29). Histochemistry showed that only scattered fibers stained for COX activity in the first biopsy, but the number of positive fibers increased with time. Immunocytochemistry, however, showed presence of CRM even in fibers lacking COX activity: the presence of inactive enzyme protein was confirmed by ELISA.

The reversibility of $\mathrm{COX}$ suggests at least two hypothetical explanations. If the genetic error affects mtDNA, there could be a gradual selection of fibers containing a majority of wild-type mitochondrial genomes over those that contain mostly mutant mtDNA. In favor of this hypothesis is the histochemical observation that fibers seem to be affected in an all-or-none fashion: it is the number of normal fibers that increases with time, not the intensity of the enzyme reaction in each fiber. Against the hypothesis, however, is the lack of evidence of maternal transmission for this disorder. If the genetic error affects nDNA, the mutation may involve a subunit that is not only tissue-specific but also developmentally regulated. Mutations of a fetal or neonatal muscle isozyme would be corrected when the mature isozyme starts to be expressed.

In patients with Leigh syndrome, there is a generalized but partial defect of COX. In a study of five patients, we found that the residual activity varied in different tissues but tended to be similar in the same tissue from different patients: it was approximately $35 \%$ of normal in brain, but only $15 \%$ in muscle, and less than $10 \%$ in liver (40). The expression of COX deficiency in cultured skin fibroblasts in most (but not all) patients suggests that prenatal diagnosis may be feasible in families with one affected child. Prenatal diagnosis was recently performed by determination of COX activity in a biopsy of chorionic villi (51). Abnormal susceptibility of the enzyme to inhibition by oxidized cytochrome $\mathrm{c}$ was reported in fibroblasts from one patient (52), but we found normal affinity of COX for reduced cytochrome $\mathrm{c}$ in muscle and brain from three other patients. The amount of CRM was variably decreased in different tissues (40), and the decrease appeared proportional to the loss of COX activity in fibroblasts (53). No alteration of the subunit pattern was found in mitochondria isolated from brain or cultured fibroblasts $(40$, 54).

In our patient with MERRF syndrome, residual COX activity varied considerably from tissue to tissue and even in different specimens from the same tissue, in keeping with maternal inheritance (46). Biochemical errors due to mutations of mtDNA ought to be generalized but variably expressed in different tissues and within each tissue depending on the relative proportion of normal and mutant mtDNA [heteroplasmy (46)]. The $\mathrm{Km}$ for cytochrome $c$ was abnormally low, suggesting a defect of the mtDNA-encoded COX II (47). Immunologic studies showed that the holoenzyme was decreased, but subunit II was decreased more than the holocomplex or the nDNA-encoded COX IV. Although the biochemical defect was confined to COX in our patient, a combined defect of complexes I and IV was reported in two members of another family with MERRF (46).

\section{MOLECULAR GENETIC STUDIES}

The dual genetic control of the enzyme makes COX deficiencies particularly interesting disorders from the genetic point of view. In theory, at least, we could envision the following genetic causes of COX deficiency: 1) mutations of nuclear genes encoding the 10 smaller COX subunits; 2) mutations of mtDNA affecting directly or indirectly the three COX genes; 3 ) mutations of genes controlling the many steps involved in the import of nDNA-encoded COX subunits from the cytoplasm into the mitochondria; and 4) mutations of regulatory genes controlling the rate of synthesis and the assembly of mtDNA and nDNAencoded subunits. Human pathology offers examples of the first two categories; COX deficiencies due to the molecular errors postulated in categories 3 and 4 have not yet been documented, but are likely to occur.

The muscle-specific COX deficiencies exemplified by the fatal and benign infantile myopathies are probably due to mutations in one of the two nDNA-encoded subunits that are known or 
presumed to be tissue specific, COX VIa or COX VIIa. This is in keeping with the apparent autosomal recessive mode of transmission of these disorders and with preliminary immunohistochemical evidence that COX VIIa is defective in muscle of patients with fatal infantile myopathy. Because a mtDNA defect has been considered in the etiology of the benign form of COX deficient myopathy, we performed Southern analysis of total muscle DNA from four patients, and found no detectable deletion of mtDNA (48). These studies, however, do not exclude the possibility that a point mutation or small deletion may affect one of the mitochondrial COX genes.

Leigh syndrome associated with COX deficiency is clearly transmitted as an autosomal recessive trait. The generalized nature of the enzyme defect suggests involvement of one of the eight nontissue-specific nuclear genes. Evidence for a nDNAencoded mutation comes also from experiments in which COXdeficient fibroblasts from a patient with Leigh syndrome were fused with a variant strain of $\mathrm{HeLa}$ cells (55). Prolonged cultivation of the hybrids in appropriate media led to preferential loss of HeLa cell mtDNA. COX activity was normal in cell clones that had lost almost all the HeLa cell mtDNA, suggesting that the enzyme defect was corrected by a nDNA-encoded factor from the HeLa parental cell. However, as mentioned above, Western analysis in different laboratories has failed to show a specific defect of a single subunit. We are performing systematic Northern analysis of mRNA extracted from different tissues of Leigh patients using cDNA probes for all available COX subunits. So far, we have found no evidence to suggest altered size or abundance of message for any subunit. Thus, Leigh syndrome might be due to the mutation of a nuclear regulatory gene controlling the assembly or stability of the enzyme, but this remains to be proven.

The maternal inheritance in MERRF syndrome suggests a mutation of mtDNA, but Southern analysis has ruled out major deletions $(46,48)$. Indirect biochemical and immunologic evidence in a patient studied by us (see above) suggested that the defect involved COX II. However, Northern and Southern blots showed that the gene for subunit II (as well as the genes for subunits I, III, IV, and VIII) was of normal size and normally transcribed (47). To document a point mutation of the gene for COX II will require direct sequencing, a task that will be complicated by the heteroplasmy, that is, the coexistence in the same tissue of normal and mutant mtDNA.

Paradoxically, direct evidence of mtDNA mutations has been obtained in the two disorders that are usually not hereditary, PEO (ocular myopathy) and KSS. We found deletions of $\mathrm{mtDNA}$ in muscle biopsies from 32 patients, 15 with typical or probable KSS and 17 with ocular myopathy (48). No deletions were found in three patients with KSS and in 27 with ocular myopathy. The deletions ranged in size from 1.3 to $7.6 \mathrm{~kb}$ and were mapped to different sites in the mtDNA, but an identical 4.9-kb deletion was found in 11 patients. One or more of the COX genes were involved in some but not all deletions; for example, only the gene for subunit III (CO3) was included in the more common $4.9-\mathrm{kb}$ deletion. The relative number of mutant mtDNA in muscle varied widely among patients, ranging from 27 to $85 \%$. We found that, in KSS, the same mtDNA deletion was found in all tissues, but the relative proportions of normal and deleted mitochondrial genomes varied from tissue to tissue. Because none of the cases studied by us was familial, and no deletion was found in muscle biopsies from the mothers of three KSS patients, it is likely that the deletions are due to spontaneous mutations of mtDNA in the oocyte or in the zygote. We have shown that the partial COX deficiency observed in muscle from patients with ocular myopathy or KSS is not a specific defect. Biochemical analysis of six mitochondrial enzymes showed that the mean activities of four enzymes of the respiratory chain-COX, succinate-cytochrome $\mathrm{c}$ reductase, rotenone-sensitive NADH-cytochrome $\mathrm{c}$ reductase, and NADH dehydrogenase-were significantly lower in muscle extracts from 22 patients with mtDNA deletions than in 20 patients without deletions, but the activities of succinate dehydrogenase and citrate synthase were not different in the two groups (48). All four affected enzymes contain one or more subunits encoded by mtDNA, whereas the two unaffected enzymes are entirely controlled by nDNA. However, the observation that all four enzymes were affected irrespective of the site of the deletion suggested that the entire mitochondrial genome may function as a single genetic unit rather than as a series of genes encoding individual enzymes. As the transcription of mtDNA is polycistronic, a deletion anywhere in the genome could affect transcription and translation, even of genes not directly encompassed by the deletion. This concept is supported by in situ hybridization studies of COX in muscle from a patient with KSS and the "common" 4.9-kb deletion (56). Fibers lacking histochemical COX reaction had a predominance of deleted mtDNA and deleted mitochondrial mRNA (showing that the deleted genomes are transcribed). Immunocytochemistry of these same fibers showed that the nuclear-encoded subunit IV was present, whereas COX II was markedly decreased or absent, despite the fact that the gene for COX II was not included in the deletion.

\section{DISCUSSION}

The complexity of COX and the related variety of clinical phenotypes due to COX deficiency offer many opportunities to gain insight into the structure, function, and control of this multisubunit enzyme. Because of the dual genetic control of COX, the study of patients may also help clarify the coordination of nuclear and mitochondrial gene expression. The availability of monospecific antibodies against the different subunits and cDNA probes for most of them should facilitate our understanding of the different COX deficiencies at the molecular level.

Most studies have been conducted in skeletal muscle, because this tissue is both highly vulnerable to COX deficiency and easily accessible. The relative uniformity of cell populations in muscle further facilitates both histochemical and biochemical investigations. Other tissues that are equally or more vulnerable to COX deficiency, such as the brain, remain to be studied. Histochemical studies of COX in the brain of normal primates has revealed a fascinating heterogeneity in the distribution of the enzyme among different neurons and within different areas of the same neuron (57). The possible existence of multiple COX isozymes in the brain could be studied by immunocytochemistry and in situ hybridization, and the presence and distribution of residual COX activity ought to be investigated by the same techniques in brains of patients with Leigh syndrome, MERRF, or other forms of COX deficiency affecting the nervous system.

Systematic analysis of cultured skin fibroblasts in patients with lactic acidosis will detect most cases of generalized COX deficiency, such as Leigh syndrome $(39,58)$, and similar studies have been suggested in liver biopsies of patients with unexplained generalized metabolic diseases (59). As interest in mitochondrial diseases in general, and in COX deficiency in particular, extends outside the area of neurology, we can expect new clinical phenotypes to be added to the already varied spectrum of the COXdeficient encephalomyopathies.

Acknowledgment. The authors dedicate this report to the memory of Aldo Danesi.

\section{REFERENCES}

1. Capaldi RA, Malatesta F, Darley-Usmar V 1983 Structure of cytochrome c oxidase. Biochim Biophys Acta 726:135-148

2. Kadenbach B, Kuhn-Nentwig L, Buge U 1987 Evolution of a regulatory enzyme: cytochrome c oxidase (complex IV). Curr Top Bioenerg 15:114161

3. Anderson S, Bankier AT, Barrell BG, DeBruijn MHL. Coulson AR. Drouin J, Eperson IC, Nierlich DP, Roe BA, Sanger F, Schreier PH, Smith AJH, Smith H, Staden R, Young IG 1981 Sequence and organization of the human mitochondrial genome. Nature 290:457-475 
4. Kadenbach B. Ungibauer BM, Jarausch J, Buge U. Kuhn-Nentwig L 1983 The complexity of respiratory complexes. Trends Biochem Sci 8:398-400

5. VanLoon APGM, Brandli AV, Schatz G 1986 The presequences of two imported mitochondrial proteins contain information for intracellular and intramitochondrial sorting. Cell 44:801-812

6. Rosenberg LE. Fenton UA. Horwich AL, Kalousck F, Kraus JP 1986 Targeting of nuclear-encoded proteins to the mitochondrial matrix: implications for human genetic defects. Ann NY Acad Sci 488:19-32

7. Zeviani M, Nakagawa M. Herbert J, Lomax MI, Grossman LI, Sherbany AA. Miranda AF. DiMauro S. Schon EA 1987 Isolation of a cDNA clone encoding subunit IV of human cytochrome c oxidase. Gene 55:205-217

8. Rizzuto R, Nakase H, Zeviani M, DiMauro S, Schon EA 1988 Subunit Va of human and bovine cytochrome c oxidase is highly conserved. Gene 69:245256

9. Zeviani M. Sakoda S. Sherbany AA, Nakase H, Rizzuto R, Samitt CE, DiMauro S. Schon EA 1988 Sequence of $\mathrm{cDNAs}$ encoding subunit Vb of human and bovine cytochrome c oxidase. Gene 65:1-11

10. Fabrizi GM. Rizzuto R, Nakase H, Mita S, Kadenbach B, Scon EA 1989 Sequence of a cDNA specifying subunit VIa of human cytochrome coxidase. Nucleic Acids Res 17:6409

11. Taanman J-W, Schrage C, Ponne N, Bolhuis P, deVries H, Agsteribbe E 1989 Nucleotide sequence of cDNA encoding subunit VIb of human cytochrome c oxidase. Nucleic Acids Res 17:1766

12. Otsuka M. Mizuno Y. Yoshida M. Kagawa Y, Ohta S 1989 Nucleotide sequence of cDNA encoding human cytochrome $c$ oxidase subunit VIc. Nucleic Acids Res 16:10916

13. Fabrizi GM. Nakase H. Mita S. Lomax MI. Grossman LI. Schon EA 1989 Sequence of a cDNA specifying subunit VIIa of human cytochrome c oxidase. Nucleic Acids Res 17:7107

14. Rizzuto R, Darras B, Francke U, Zeviani M, Mengel T, Walsh FS, Kadenbach B, DiMauro S, Schon EA 1989 A gene specifying subunit VIII of human cytochrome c oxidase is localized to chromosome 11 and is expressed in both muscle and non-muscle tissues. J Biol Chem 264:10595-10600

15. French JH, Sherard ES. Lubell H, Brotz M, Moore CL 1972 Trichopoliodystrophy: I. Report of a case and biochemical studies. Arch Neurol 26:229 244

16. Van Biervliet JPAM. Bruinvis L, Ketting D. DeBree PK, Heiden EV, Wadman SK, Willems JL. Bookelman H. VanHaelst U. Monnens LA 1977 Hereditary mitochondrial myopathy with lactic acidemia, a DeToni-Fanconi-Debre syndrome, and a defective respiratory chain in voluntary striated muscles. Pediatr Res 11:1088-1093

17. Willems JL, Monnens LAH. Trijbels JMF, Veer-Kamp JH, Meyer AE, vanDam K, van Haelst U 1977 Leigh's encephalomyelopathy in a patient with cytochrome c oxidase in muscle tissue. Pediatrics 60:850-857

18. DiMauro S. Mendell JR. Sahenk A, Bachman D, Scarpa A. Scofield R. Reiner C 1980 Fatal infantile mitochondrial myopathy and renal dysfunction due to cytochrome c oxidase deficiency. Neurology 30:795-804

19. Heiman-Patterson T, Bonilla E, DiMauro S, Foreman J, Schotland DS 1982 Cytochrome c oxidase deficiency in a floppy infant. Neurology 32:898-900

20. Minchom PE. Dormer RL, Hughes IA, Stansbie D. Cross AR, Hendry GAF, Jones OTG, Johnson MA. Sherratt HSA. Turnbull DM 1983 Fatal infantile mitochondrial myopathy due to cytochrome c oxidase deficiency. J Neurol Sci 60:453-463

21. Muller-Hocker J, Pongratz D, Deufel T, Trijbels JMF, Endres W, Hubner G 1983 Fatal lipid storage myopathy with deficiency of cytochrome c oxidase and carnitine. Virchows Arch 399:11-23

22. Bresolin N, Zeviani M, Bonilla E, Miller RH, Leech RW, Shanske S, Nakagawa M. DiMauro S 1985 Fatal infantile cytochrome c oxidase deficiency: decrease of immunologically detectable enzyme in muscle. Neurology 35:802-812

23. Zeviani M. Nonaka I, Bonilla E, Okino E, Moggio M, Jones S, DiMauro S 1985 Fatal infantile mitochondrial myopathy and renal dysfunction due to cytochrome c oxidase deficiency: immunological studies in a new patient. Ann Neurol 17:414-417

24. Sengers RCA. Trijbels JMF, Bakkeren JAJM, Ruitenbeek W, Janssen AJM, Stadhouders AM. Laak HJ 1983 Deficiency of cytochromes b and $a_{3}$ in muscle from a floppy infant with cytochrome oxidase deficiency. Eur J Pediatr 141:178-180

25. Nonaka I, Koga Y. Shikura K, Kobayashi M, Sugiyama N, Okino E, Nihei K. Tojo M, Segawa M 1988 Muscle pathology in cytochrome c oxidase deficiency. Acta Neuropathol (Berl) 77:152-160

26. Zeviani M, VanDyke DH, Servidei S, Bauserman SC, Bonilla E, Beaumont ET. Sharda J, VanderLan K, DiMauro S 1986 Myopathy and fatal cardiopathy due to cytochrome c oxidase deficiency. Arch Neurol 43:1198-1202

27. Hart Z, Chang $\mathrm{CH} 1988$ A newborn infant with respiratory distress and stridulous breathing. J Pediatr 113:150-155

28. Boustany RN, Aprille JR. Halperin J, Levy H. DeLong GR 1983 Mitochondrial cytochrome deficiency presenting as a myopathy with hypotonia, external ophthalmoplegia, and lactic acidosis in an infant and as fatal hepatopathy in a second cousin. Ann Neurol 14:462-470

29. DiMauro S, Nicholson JF, Hays AP, Eastwood AE, Papadimitriou A. Koenigsberger R, DeVivo DC 1983 Benign infantile mitochondrial myopathy due to reversible cytochrome c oxidase deficiency. Ann Neurol 14:226-234
30. Zeviani M, Peterson P, Servidei S, Bonilla E, DiMauro S 1987 Benign reversible muscle cytochrome $\mathrm{c}$ oxidase deficiency. A second case. Neurology 37:6467

31. Servidei S, Bertini E, Dionisi-Vici C, Miranda AF, Ricci E, Silvestri G, Bonilla E, Tonali P, DiMauro S 1988 Benign infantile mitochondrial myopathy due to reversible cytochrome $c$ oxidase deficiency: a third case. Clin Neuropathol $7: 209-210$

32. Johnson MA, Turnbull DM, Dick DJ, Sherratt HSA 1983 A partial defect of cytochrome $\mathrm{c}$ oxidase in chronic progressive external ophthalmoplegia. $\mathrm{J}$ Neurol Sci 60:31-53

33. Muller-Hocker J, Pongratz D, Hubner G 1983 Focal deficiency of cytochrome c oxidase in skeletal muscle of patients with progressive external ophthalmoplegia. Virchows Arch 402:61-71

34. Byrne E, Dennett X, Trounce I, Henderson R 1985 Partial cytochrome oxidase deficiency in chronic progressive external ophthalmoplegia. J Neurol Sci 71:257-271

35. Miyabayashi S, Narisawa K, Tada K, Sakai K, Kobayashi K, Kobayashi $Y$ 1983 Two siblings with cytochrome c oxidase deficiency. J Inherited Metab Dis 6:121-122

36. Miyabayashi S, Ito T, Abukawa D, Narisawa K, Tada K, Tanaka M, Ozawa M, Droste M, Kadenbach B 1987 Immunochemical study in three patients with cytochrome c oxidase deficiency presenting Leigh's encephalomyelopathy. J Inherited Metab Dis 10:289-292

37. Goebel HH, Bardosi A, Friede RL, Kohlschutter A, Alboni M, Siemes H 1986 Sural nerve biopsy studies in Leigh's subacute necrotizing encephalomyelopathy. Muscle Nerve 9:165-173

38. Arts WFM, Scholte HR, Loonen MCB. Przyrembel H, Fernandes J, Trijbels JMF, Luyt-Houwen IEM 1987 Cytochrome c oxidase deficiency in subacute necrotizing encephalomyelopathy. J Neurol Sci 77:103-115

39. Robinson BH, DeMeirleir L, Glerum M, Sherwood G, Becker L 1987 Clinical presentation of mitochondrial respiratory chain defects in NADH-coenzyme $Q$ reductase and cytochrome oxidase: clues to pathogenesis of Leigh's disease. J Pediatr 110:216-222

40. DiMauro S, Servidei S, Zeviani M, DiRocco M, DeVivo DC, DiDonato S, Uziel G, Berry K, Hoganson G, Johnsen SD, Johnson PC 1987 Cytochrome c oxidase deficiency in Leigh syndrome. Ann Neurol 22:498-506

41. Angelini C, Bresolin N, Pegolo G, Bet L, Rinaldo P, Trevisan CP, Vergani L 1986 Childhood encephalomyopathy with cytochrome c oxidase deficiency, ataxia, muscle wasting, and mental impairment. Neurology 36:1048-1052

42. DiRocco M, Veneselli E, Ciccone MO, Taccone A, Stroppiano M, Cottafava F 1988 Cytochrome c oxidase deficiency in three patients with Leigh's disease. J Inherited Metab Dis 11:189-192

43. Prick MJJ, Gabreels FJM, Trijbels JMF, Janssen AJM, LeCoultre R, vanDam K, Jaspar HHT, Ebels EJ, op de Coul AAW 1983 Progressive poliodystrophy (Alpers disease) with a defect in cytochrome $\mathrm{aa}_{3}$ in muscle: a report of two unrelated patients. Clin Neurosurg 85:57-70

44. Rosing HS, Hopkins LC, Wallace DC, Epstein CM, Weidenheim K 1985 Maternally inherited mitochondrial myopathy and myoclonic epilepsy. Ann Neurol 17:228-237

45. Berkovic SF, Carpenter S, Karpati G, Andermann F, Andermann E, Shoubridge E. Arnold D 1987 Cytochrome c oxidase deficiency: a remarkable spectrum of clinical and neuropathologic findings in a single family. Neurology 37:223(abstr)

46. Wallace DC, Zheng X, Lott MT, Shoffner JM, Hodge JA, Kelley RI, Epstein CM, Hopkins LC 1988 Familial mitochondrial encephalomyopathy (MERRF): genetic, pathophysiological, and biochemical characterization of a mitochondrial DNA disease. Cell 55:601-610

47. Lombes A, Mendell JR, Nakase $H$, Barohn RJ, Bonilla E, Zeviani M, Yates AJ, Omerza J, Gales TL, Nakahara K, Rizzuto R, Engel WK, DiMauro S 1989 Myoclonic epilepsy and ragged-red fibers with cytochrome c oxidase deficiency: neuropathology, biochemistry, and molecular genetics. Ann Neurol 26:20-33

48. Moraes CT, DiMauro S, Zeviani M, Lombes A, Shanske S, Miranda AF, Nakase H, Bonilla E, Werneck LC, Servidei S, Nonaka I, Koga Y, Spiro AJ, Brownell AK, Schmidt B, Schotland DL, Zupanc M, DeVivo DC, Schon EA, Rowland LP 1989 Mitochondrial DNA deletions in progressive external ophthalmoplegia and Kearns-Sayre syndrome. N Engl J Med 320:12931299

49. Bardosi A, Creutzfeldt W, DiMauro S, Felgenhauer K, Friede RL, Goebel HH, Kohlschutter A, Mayer G, Rahlf G, Servidei S, VanLessen G, Wetterling T 1987 Myo-, neuro-, gastrointestinal encephalopathy (MNGIE syndrome) due to partial deficiency of cytochrome c oxidase. Acta Neuropathol 74:248258

50. DiMauro S, Zeviani M, Servidei S, Prelle A, Miranda AF, Bonilla E, Schon EA 1988 Biochemical and molecular aspects of cytochrome c oxidase deficiency. In: DiDonato S, DiMauro S, Mamoli A, Rowland LP (eds) Advances in Neurology, Vol 48. Raven, New York, pp 93-105

51. Muller-Hocker J, Droste M, Kadenbach B. Pongratz D, Hubner G 1989 Fatal mitochondrial myopathy with cytochrome $c$ oxidase deficiency and subunitrestricted reduction of enzyme protein in two siblings. An autopsy-immunocytochemical study. Hum Pathol 20:666-672

51a. Tritschler HJ, Bonilla E, Lombes A, Andreetta F, Servidei S, Schneider B, 
Miranda AF, Schon EA, Kadenbach B, DiMauro S 1990 Differential diagnosis of fatal and benign cytochrome $c$ oxidase deficient myopathies of infancy: an immunohistochemical approach. Neurology (in press)

52. Ruitenbeek W, Sengers R, Albani M, Trijbels F, Janssen A, vanDiggelen O, Bakkeren J 1988 Prenatal diagnosis of cytochrome c oxidase deficiency by biopsy of chorionic villi. [letter] N Engl J Med 319:1095

53. Glerum M, Robinson BH, Spratt C, Wilson J, Patrick D 1987 Abnormal kinetic behavior of cytochrome $c$ oxidase in a case of Leigh disease. Am J Hum Genet 41:584-593

54. Glerum M, Yanamura W, Capaldi RA, Robinson BH 1988 Characterization of cytochrome $c$ oxidase mutants in human fibroblasts. FEBS Lett $236: 100$ 104

55. Miranda AF, Ishii S, DiMauro S, Shay JW 1989 Cytochrome c oxidase deficiency in Leigh's deficiency: genetic evidence for a nuclear DNA-encoded mutation. Neurology 39:697-702

56. Mita S, Schmidt B, Schon EA, DiMauro S, Bonilla E 1989 Detection of deleted mitochondrial genomes in cytochrome c oxidase-deficient muscle fibers of a patient with Kearns-Sayre syndrome. Proc Natl Acad Sci USA 86:95099513

57. Wong-Riley MTT 1989 Cytochrome oxidase: an endogenous metabolic marker for neuronal activity. Trends Neurosci 12:94-101

58. DeVivo DC, Tress E, DiMauro S 1986 Cultured human skin fibroblasts and cerebral oxidative metabolic defects: normative data and Leigh's syndrome. Ann Neurol 20:423-424

59. Aprille JR 1985 Tissue specific cytochrome deficiencies in human infants. In: Quagliariello E, Slater EC, Palmieri F, Saccone C, Kroon AM (eds) Achievements and Perspectives of Mitochondrial Research, Vol II. Elsevier, New York, pp 465-476

60. Schon AE, Bonilla E, Lombes A, Moraes CT. Nakase H. Rizzuto R. Zeviani M, DiMauro S 1988 Clinical and biochemical studies on cytochrome c oxidase deficiencies. Ann NY Acad Sci 550:348-359 